\title{
El proceso de traducción entre español y huichol
}

\author{
José Luis ITURrioz LeZA / Julio RAMíREZ DE LA CRUZ \\ Universidad de Guadalajara \\ jliturrioz@yahoo.com.mx
}

Recibido: 29 de noviembre de 2011

Aceptado: 5 de marzo de 2012

\section{RESUMEN}

Las reflexiones vertidas en este trabajo parten de la experiencia propia en la traducción de textos técnicos de los dominios lingüístico, jurídico y médico del español al huichol, una lengua mexicana de la familia yutoazteca, caracterizada tipológicamente como polisintética, centralizante, verbalizante y explicitante. Por razones de espacio, nos centramos en la traducción de la Gramática Didáctica del Huichol, elaborada a lo largo de años y de la que conservamos varios borradores. La competencia traductorial abarca además de la competencia gramatical y léxica, una competencia pragmática textual y una competencia cultural. Una traducción debe hacerse además en conformidad con las características tipológicas de la lengua meta.

Palabras clave: traducción, competencia pragmática, competencia textual, competencia cultural, adecuación tipológica.

The translation process between Huichol and Spanish

\begin{abstract}
This paper is based on our own experience in translating technical texts belonging to the fields of linguistics, law and medicine from Spanish to Huichol, a Mexican Uto-aztecan language which can be characterized as polysynthetic, centralizing, verb centered and highly explicit. We focus on the analysis of several drafts documenting the process of the translation of the Gramática Didáctica del Huichol. Translation competence involves grammatical and lexical competence, as well as textual, pragmatic and cultural competence.
\end{abstract}

Keywords: translation, pragmatic competence, text competence, cultural competence, typological adecuacy. 
Sumario: Introducción. 1. La situación actual. 2. La competencia traductora. 3. La competencia gramatical. 4. La competencia léxica. 5. Traducción y pragmática. 6. La adecuación tipológica. 7. La competencia textual. 8. La competencia cultural. 9. Conclusiones. 10. Referencias bibliográficas. Abreviaturas.

\section{Introducción}

El huichol es una lengua de la familia yuto-azteca cercanamente emparentada con el náhuatl, hablada por unas 40,000 personas en el occidente de México en la confluencia de los estados Jalisco, Nayarit, Durango y Zacatecas. Un estudio diacrónico de los préstamos muestra que entraron en contacto con los colonizadores españoles desde el siglo XVI (Iturrioz 2008). Es una etnia casi sin historia documental escrita (Rojas 1993), aunque con una rica tradición hablada que incluye las crónicas. La primera traducción que se lleva a cabo es la del catecismo, a principios del XX, y apenas en los últimos decenios la lengua se ha abierto a dominios discursivos nuevos como el lingüístico, el jurídico y el médico. La situación propicia una reflexión acerca del contacto entre lenguas a través de la traducción y, sobre todo, acerca de las dificultades que implica la comunicación entre dos lenguas tan distantes desde el punto de vista tipológico (Iturrioz, en prensa) y del desarrollo discursivo.

\section{La situación actual}

La traducción es un fenómeno muy importante de comunicación intercultural, un instrumento eficaz para aprender una segunda lengua y para el desarrollo de la competencia en la propia lengua, a la vez que proporciona material valioso para la gramática contrastiva y para la teoría del lenguaje. Si la teoría lingüística puede ayudar en los procesos de traducción, la investigación de los procesos de traducción puede ser relevante para la construcción de una teoría general del lenguaje.

Para traducir del inglés al español o viceversa se dispone de valiosas herramientas como diccionarios, gramáticas y estudios elaborados a partir de las experiencias de otros especialistas, además de cursos o programas especializados. No es lo mismo traducir entre lenguas que se encuentran en etapas equiparables de desarrollo que traducir a una lengua que no ha tenido un desarrollo similar en un dominio cognitivo dado. En tales casos, la traducción no tiene nada de mecánico, tiene que ser más creativa, y por ello más transparente y accesible a la reflexión.

En el Departamento de Estudios de Lenguas Indígenas de la Universidad de Guadalajara (México) llevamos a cabo traducciones del huichol al español y en la dirección opuesta. En el primer caso se trata de textos de la literatura tradicional; en el segundo caso se trata de textos técnicos de medicina, lingüística, legislación, pedagogía. Las experiencias acumuladas servirán de base para una guía del traductor; la otra base es la descripción contrastiva de las dos lenguas desde el nivel del enunciado hasta el nivel textual. 
Una de las traducciones más complejas que hemos emprendido hasta la fecha es la del primer volumen de la Gramática Didáctica del Huichol, cuya finalidad principal es la formación de maestros para la enseñanza del huichol, se ubica en un nivel medio de complejidad. El texto en español del primer volumen tiene casi 300 páginas y está dedicado a la estructura fonológica de la lengua huichola en contraste con la del español y a fundamentar un sistema de escritura adecuado. Incluye numerosos cuadros informativos sobre aspectos históricos, literarios, psicológicos y antropológicos de la escrituralidad, donde se utilizan gran cantidad de palabras conceptualmente complejas: fonema, rasgo distintivo, normativo, sintaxis, estilos, géneros, registro, diafásico, diastrático, geolingüístico, sociolingüistico, oralidad y escrituralidad, sociolecto, geolecto y muchos otros. Incluye un glosario de casi 1,000 términos utilizados en el texto. Disponemos de varios borradores que documentan las fases sucesivas del proceso.

Con la traducción de la Ley General de Derechos Lingüisticos de los Pueblos Indígenas hemos querido hacer una contribución a la formación de una nueva tradición discursiva, la jurídica.

Otro reto importante ha sido la traducción de un folleto informativo sobre el SIDA que se utiliza en la Secretaría de Salud Pública del Estado de Jalisco: datos biológicos, vías de transmisión, síntomas, medidas preventivas.

\section{La competencia traductora}

La traducción es una compleja operación que involucra todos los subsistemas de organización de las lenguas (gramatical, semántico, pragmático) y todos los niveles de complejidad (de la palabra al texto). El traductor debe poseer además del conocimiento del léxico y la gramática, una competencia comunicativa textual para poder elegir entre las variantes diafásicas de la lengua, la formal y la informal, la conversacional y la narrativa, la oral y la escritural. Si lo que se traduce es finalmente un texto, la competencia, restringida a la capacidad de generar oraciones bien formadas, no puede dar cuenta de ese proceso. Es necesaria una visión más abarcadora y dinámica de la traducción como una operación lingüística compleja que integra e interrelaciona todas estas áreas de la actividad lingüística. El análisis de los procesos de traducción requiere y propicia, además, una visión del lenguaje no enfocada a una sola lengua. El traductor y el traductólogo deben adoptar una visión descentrada y contrastiva, porque la traducción no se puede entender exclusivamente desde la perspectiva de una sola lengua. Son muy relevantes las consideraciones de orden tipológico.

La traducción no es simplemente un problema de correspondencia entre léxicos y gramáticas. Son cruciales los aspectos semánticos, pero la semántica no se puede restringir al significado de las palabras, ya que la oración y el texto son también niveles de construcción del significado. Un texto es una operación comunicativa en la que desempeñan un papel importante la pragmática, la tipología de los textos y el contexto cultural. La importancia de la competencia cultural se hace tanto más evidente cuanto más diferentes son las respectivas culturas. 
Partamos de un primer ejemplo aparentemente sencillo, con el que se puede ilustrar todos los componentes a los que hemos hecho referencia. Si queremos traducir del huichol Wiexu temité upitżarie, título de una colección de cuentos de un autor huichol, empezaríamos descartando una opción demasiado literal como "lo que fuimos dados por Wiexu", que preserva propiedades gramaticales del huichol, pero violenta las reglas gramaticales del español, donde el beneficiario no es candidato a la función de sujeto en la construcción pasiva. Podemos remediar la situación optando por una construcción un poco más libre, pero algo renqueante como Con lo que fuimos dotadas por Wiexu o en activa Lo que Wiexu nos donó. La opción más libre, la más alejada del título huichol, pero la más adecuada tanto a la estructura como a la tradición literaria del español, es la frase Los dones de Wiexu. Si en español no tenemos una construcción sintáctica equivalente a la frase original huichola, a la inversa no existe en huichol una equivalencia para el término "don, regalo"; debe expresarse mediante una estructura predicativa lo que en español se puede expresar mejor con un término nominal, una diferencia tipológica muy importante. En el caso de Con lo que fuimos dotadas por Wiexu nos tomamos la libertad de introducir el género femenino, que no está expresado en el enunciado original, pero el traductor debe conocer todo el texto antes de traducir el título y sabe por ello y por un conocimiento de la cultura huichola que va más allá de este texto, que Wiexu reparte sus dones sólo entre las mujeres, porque se trata de la habilidad para tejer y bordar. Sin embargo, debemos considerar si es una decisión apropiada anunciar eso desde el título o si es mejor dejar que el lector lo descubra en la lectura del texto. La frase más escueta puede parecer la más adecuada para un título. Estas consideraciones pertenecen a la pragmática textual. Así, a las reflexiones de orden sintáctico y semántico se han sumado otras de orden comunicativo y cultural. Estos diferentes componentes trabajan en red, de una manera complementaria, cooperativa en toda actividad lingüística real.

\section{La competencia gramatical}

Para realizar una buena traducción, se requiere en primer lugar un dominio pleno de la gramática de las dos lenguas. La importancia de la competencia gramatical se hace más transparente cuando falla. A principios del siglo XX se llevó a cabo una traducción del catecismo al huichol publicada bajo el título Ensayo Catequístico en Español y Huichol (Velasco 1906). El presbítero que firma el catecismo recurrió para ello a la ayuda de personas alejadas desde niños de su entorno cultural, internadas en colegios donde no aprendían su lengua ni en su lengua, eran instruidos en la religión cristiana y no en la propia, por lo que no seguían desarrollando su conocimiento. En la versión huichola detectamos pruebas de su competencia gramatical limitada.

(1) Yusi niukíeya ?'kítsikayate me-nitamámatatini. Yu-haikatł me-muhaititia yutsitsie

me-mimiemetexi, hiipátí ?atahuutatì ta?iwaáma me-te-hetsiena miemetexi. 
"Los Mandamientos de la Palabra de Dios son diez. Los tres primeros son relativos a

dios, y los otros siete relativos al provecho del prójimo."

En este pasaje se trata al infinitivo ? kitsika "mandamiento", núcleo del sintagma nominal Yusi niukieya ?"̈kitsikayate "los mandamientos de la palabra de Dios" como si tuviera el rasgo [+animado], a juzgar por las marcas de plural en los predicados, las cuales sólo pueden aparecer cuando el sujeto es animado: $m e-$ '3.PL:ANIM', te- 'CON:PL:ANIM', $y u$ - 'ANIMADO'. La frase debería quedar en la forma:

(1a) Yusi niukíeya ? kítsikateya kanitamámatatinni. Haikáti muhaititia yutsitsie mimiemetexi, hiipáṫ ?atahuutatì ta?iwaáma mötiwahetsiena miemetexi.

En el ejemplo (2) se eligió el alternador referencial equivocado, debe ser -me, ya que se trata de una acción realizada por el mismo sujeto, a saber todos (los humanos):

(2) Tukari meye?aní tanáiti tekwi-yu (=> tekwi-me) temiwatíyeixiani te?ayeneniereti.

"El día llegará en que todos después de haber muerto saldremos vivos."

El debilitamiento de la competencia gramatical se manifiesta también en las interferencias con el español al usar, por ejemplo, la adposición kimana como una conjunción, algo poco conforme con la estructura morfosintáctica de una lengua de tipo centralizante donde los conectores son sufijos en la última posición de la palabra predicativa (Iturrioz, en prensa):

(3) Nemátsipitłaniki kïmana ?akipuri mitawené, ?a?iyari mitatarire. "Para absolverte de manera que tu espíritu se libere, tu alma se limpie."

Muchos usos del clítico ke(name) parecen basarse en la conjunción que:

(4) Ya petikuhławétł kenaáme tatakuri pemłhayewa pemłka ke tawari ka?iwewieni.

"Prométele que dejarás los pecados y que no volverás a cometerlos."

\section{La competencia léxica}

En la traducción técnica y científica, uno de los problemas es desde luego el de la terminología, pero no hay que confundir término con término básico o etiqueta y mucho menos partir de la premisa de que a cada término de la lengua de partida debe corresponder un término de la misma categoría léxica en la lengua meta. La expresión de conceptos debe ser abordada desde la perspectiva de los niveles de organización superiores a la palabra. La mayoría de los nuevos términos introducidos en nuestras traducciones no son etiquetas. En algunos casos se decidió aceptar présta- 
mos para conceptos centrales de la teoría (wukari para vocal, punema para fonema, ?aripawetu para alfabeto), en otros dar a palabras ya existentes una acepción metafórica (teiki kwaxi "cola hacia arriba" para el saltillo) o crear un término nuevo y en tal caso decidir si se escoge un término etiqueta o se forma uno más descriptivo que puede ser una composición (combinación de fonemas $=>$ punema niiyari 'fonemaunir-COMP', reglas de combinación $=>$ nitiyá xekirayaari 'combinación-reglaCOMP'), o puede equivaler a un enunciado entero como teitéri memiiretz yiki memeu$k u^{\text {?anene }}$ '3PL:SUJ:ANIM-MOD-TRAV-DISP-PL-ser' "personas numerosas que están separadas" para grupos sociales; secuencias de fonemas en la sílaba $\Rightarrow>$ punemate ke mirreuyukuweiyatika tsirawa taitá 'fonema-PL cómo MOD-GRAD-TRAV-REFL-DISPweiya-DISTR sílaba dentro de' "cómo se distribuyen los fonemas en diversas posiciones separadas dentro de una sílaba". La información que constituye el concepto se expresa a través de varios morfemas gramaticales dentro de la palabra predicativa, acompañada de otros dos lexemas. La elección entre las diversas técnicas tiene que ver también con la organización del texto y la pragmática comunicativa, incluyendo los destinatarios del texto.

Los aspectos terminológicos no se deben poner en un primer plano en la traducción, no son el problema central ni el primero a resolver cuando la lengua meta es polisintética, explicitante, centralizante y verbalizante, como es el caso del huichol (Iturrioz, en prensa). Atenerse a este procedimiento obliga a copiar la estructura de la lengua. Probablemente los lectores no podrían entender el producto. En primer lugar no existe una sóla manera de traducir un término, sino varias o muchas alternativas de expresar lo mismo, dependiendo de la situación y del registro elegido. La estructura de la oración en huichol es tan diferente que, donde el español requiere un término técnico nominal, el huichol puede prescindir de él, porque puede expresar lo mismo dentro de la palabra predicativa.

La frase sonido palatal se puede traducir como yuari tekuumaritsiemieme 'sonido paladar-de-procedente', haciendo referencia explícita al paladar, el órgano en que se basa la clasificación de este sonido. Si concentramos más la información eliminando lo redundante, nos queda el término tekuumaritsiemieme (-te 'PL'), y más concentrado todavía tekuumarikame(te). Si por el contario queremos disponer de términos más descriptivos, por ejemplo en las explicaciones didácticas, podemos recurrir a alguna de las estructuras siguientes, añadiendo cada vez más elementos significativos:

1. wayuyepináti miyutériwa "que se articula apachurrándose dentro"

2. není teikł heutipináti miyutériwa "que se pronuncia apachurrando la lengua hacia arriba"

3. temutatériwatsie není teiki heutitunátì "cuando pronunciamos arqueando la lengua hacia arriba"

4. yuari miyutériwa není hixiapa teikì meuyutipinánitsie "sonido que se articula apachurrando la lengua por el centro hacia arriba"

Ninguna de estas traducciones es mejor que las demás, ya que la evaluación debe hacerse atendiendo a diversos criterios como las funciones de todo acto comunicativo: 
1. quiénes son los destinatarios y qué nivel de conocimientos previos se presuponen

2. finalidad: ¿se trata de informar o de formar, o de formar para enseñar?

3. el medio: si el libro va a ser leido por cada lector o va a servir nada más como herramienta del maestro

4. el carácter descriptivo o explicativo del pasaje.

En suma, la terminología no puede verse desconectada de la redacción o elaboración del texto. En el proceso de traducción, el texto debe constituir la perspectiva más general desde la que se regula todo el proceso. La terminología recogida en el glosario es en realidad un producto y no la base de la traducción, un resultado de un proceso de redacción de textos.

Jakobson (1981:68) estableció una conexión interesante entre la traducción de una lengua a otra y los procesos intralingüísticos de sustitución de unos signos por otros semánticamente equivalentes: "El significado de un signo lingüístico equivale a su traducción a algún otro tipo de signo alternativo, especialmente un signo en el que aquel esté más plenamente desarrollado." Pensaba en el caso prototípico de las definiciones. Todos estos términos designan un sonido palatal, pero lo hacen de manera diferente, concretamente con un grado de mayor o menor descriptividad. Tekumarikame es un término derivado de tekumari "paladar duro"; aunque no identifica una propiedad inherente del sonido, nos remite al paladar, que es el lugar de articulación, causalmente relacionado con sus propiedades inherentes. Tekumaritsiemieme nos dice de manera explícita que se trata de un sonido que se origina en el paladar. Wayuyepinati mizuteriwa contiene referencias al estrechamiento que se produce entre la lengua y el paladar. Todavía más descriptivo es el término neni teiki heutitunatí míyuteríwa que hace referencia a la misma situación, pero utilizando la palabra que designa la lengua y describiendo mediante un adverbio la posición elevada de la misma. En temutateriwatsie neni teiki heutitunatì se introduce adicionalmente la categoría de persona, mientras que el anterior es reflexivo/impersonal. El

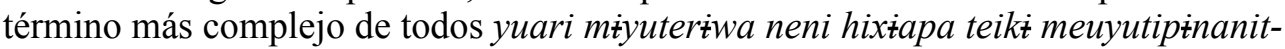
sie "sonido que se articula cuando se apachurra la lengua en el centro hacia arriba" hace explícito que se trata de un sonido que se produce elevando el dorso de la lengua para estrecharlo contra la bóveda del paladar.

\section{Traducción y pragmática}

Todos estos términos son adecuados, dependiendo de lo que se quiera obtener con ellos. Los términos etiqueta son más propios de un lenguaje técnico, donde los receptores tienen los conocimientos previos necesarios para la comprensión del texto, los más descriptivos son más aptos para las explicaciones que se pueden impartir a un público menos preparado, más aptos por tanto para la aplicación didáctica. En un texto con intenciones formativas es conveniente hacer uso de todos ellos, dependiendo de la situación comunicativa dentro de cada fase del texto, si se trata de una definición, de una explicación o de un ejercicio práctico. La cuestión de la 
terminología no puede plantearse sólo desde la perspectiva del léxico, con independencia de los niveles superiores de organización, y desde la perspectica semántica, desligada de la pragmática.

Eugene Nida distingue dos tipos de equivalencia que se pueden seguir como principios complementarios orientadores de la traducción:

- la formal (FE), básicamente "orientada a la fuente", a la lengua de partida, al emisor y

- la dinámica (DE), básicamente orientada a la meta, al receptor y su respuesta.

A la primera se la ha llamado tradicionalmente literal o apegada. Vamos a comparar dos maneras de traducir la frase ch es un sonido palatal,

a) ch yuari tekuumaritsie mieme pihïiki "ch es un sonido proveniente del paladar"

b) ch wayuyepináti miyutériwa "ch se pronuncia arqueando la lengua"

La primera es bastante apegada al original, es una construcción sintáctica casi calcada; la segunda, por el contrario, expresa el mismo concepto utilizando recursos morfológicos, mucho más acordes con el genio de la lengua: ye- indica que tiene lugar en el interior de un espacio (la boca) y $w a$ - hace referencia al encorvamiento del dorso de la lengua hacia el paladar; ni el paladar ni la lengua ni el dorso necesitan ser mencionados mediante nombres.

Desde la perspectiva de la lengua de partida la primera tendencia es asimilativa y la segunda acomodativa. Son las dos tendencias contrapuestas de toda conducta adaptativa. Es característico de una traducción acomodativa que los ejemplos ilustrativos utilizados no sean ajenos a la cultura de la lengua meta, ajustar la redacción al perfil de los lectores: su edad, su nivel de conocimientos, la finalidad formativa, informativa o recreativa.

En el Ensayo Catequístico predomina la tendencia asimilativa. Muchos términos centrales quedan sin traducir por los recelos del presbítero a que los conceptos cristianos se contaminaran con adherencias de una religión considerada como supersticiosa e idolátrica. El principio de adaptación al receptor choca fácilmente con el principio de preservación del contenido cognitivo. Para dios se utiliza la palabra yutsi, resultante de una adaptación fonológica reciente de la palabra española; por el contrario, la acomodación gramático-semántica se manifiesta en la formación del plural yutsitsixi, propia de los nombres que designan grupos sociales no huicholes, en este caso los dioses de una religión politeista. La traducción de la Biblia, 60 años después por parte de miembros del ILV (Instituto Lingüístico de Verano), se atiene más bien al principio de utilizar los recursos ya existentes en la lengua y la cultura metas para facilitar la comprensión y aceptación de los contenidos. La palabra dios se traduce como kakaìyari; la Biblia tiene como título Kakaìyari Niukieya Xapaya$r i$ "Libro de la palabra de Dios". Al traducir dios por kakaiyaari se corre el riesgo de una interpretación desde la cultura de la lengua meta: los kakatyaaríxi son ancestros que regresaron a la naturaleza materializados en las rocas. 
Otra razón de que muchos términos del catecismo se dejaran sin traducir puede haber sido el desconocimiento por parte del traductor huichol tanto de la religión cristiana como de la huichola. Para el término trinidad se pudo haber creado un término como Haikaxaitsiekame a partir de haika "tres" y xaita "único, mismo", similar al término alemán Dreieinigkeit "tresunidad". En el caso de hereje o de cismáti$c o$, se podrían haber obtenido fácilmente términos descriptivos a partir de las definiciones que acompañan a estas palabras en el mismo texto, a falta de términos etiqueta convencionalizados:

(5) Keeháte mepiherejes. Xeime yuwapame maistł́arika memi't́kita, kateyupanitsie mieme. "¿Quiénes son herejes? Los que enseñan otra doctrina diferente de la de la Iglesia."

(6) ¿Keeháte mepicismáticos? Teyupani xeime memiwewieki xaitsie yuwapame. “QQuiénes son cismáticos? Los que quieren formar una Iglesia aparte."

Los signos complejos no se toman del léxico, sino que debe ser construidos con ayuda del componente gramatical, a partir de elementos preexistentes en el léxico: waparika "cambiar, modificar", maitsitźarika "hacer recitar, enseñar", 'ìkitsika "mostrar, señalar". Cuando un traductor no encuentra en el diccionario de la lengua meta un equivalente lexical, en su lugar construye una expresión compleja. El problema es que los términos descriptivos están más expuextos a la variación semántica e interpretativa que los términos etiqueta convencionalizados, ya que su significado y sentido dependen no solo del léxico, sino tanto o más del texto como del conocimiento de un dominio cultural.

La importancia de la competencia pragmática se nos hace también más consciente cuando falla. En el Ensayo Catequistico, con frecuencia se emplean formas propias de la comunicación oral, informal, cotidiana en una situación de distancia comunicativa como es un rezo, por ejemplo palabras donde la marca de caso se afija directamente a morfemas personales ligados: taki naniukani "ruega por nosotros" en lugar de taheki naniukani. La forma coloquial taki puede ser adecuada en el cuestionario de la confesión, donde el confesante trata de crear una atmósfera de familiaridad, de cercanía, hasta de intimidad, aunque en su valoración, en la condena de los pecados y en la imposición de la penitencia adopta un estilo más formal, severo, de autoridad. En los textos doctrinales como el Credo no son las más apropiadas.

En la traducción del catecismo se presentan algunos errores atribuibles a la falta de competencia pragmática comunicativa, relacionados con el orden de palabras y la formación de oraciones interrogativas.

Orden de palabras. El orden básico de los constituyentes centrales de la oración en huichol es SOV, pero este orden se ha modificado siguiendo el patrón predominante del español SVO con el fin de hacer corresponder en lo posible una a una las palabras en la columna del texto español y del huichol, lo que sin duda respondía al deseo de facilitar al presbítero el control de la equivalencia de la traducción con el original, contraviniendo las intuiciones del traductor; el calco sintáctico enturbia la percepción de las relaciones sintácticas y entorpece los aspectos pragmáticos de la comunicación. Aunque es correcto el orden de a), es una construcción marcada, con- 
sistente en la dislocación del OD, y en el Ensayo Catequístico aparece sin embargo con mayor frecuencia que la construccion básica $b$ ).

(7) ¿Quién hizo el mundo?
a) ¿Kepái p-i-ta-wewi
kiekari?
quién SEC-3SG:PAC-TERM-hacer:PERF mundo
b) Kepái kiekari p-u-ta-wewi

Enunciados interrogativos. Muchas veces las preguntas cerradas (de si/no) son construidas por el traductor sin el prefijo interrogativo, indicando que es una pregunta sólo por el signo gráfico de interrogación. Es un calco del español que altera gravemente la pragmática comunicativa. (8a) sólo se puede entender como un enunciado asertivo. La construcción correcta es ( $8 \mathrm{~b})$, donde el asertor primario $p \dot{\boldsymbol{t}}$ - es sustituido por el afijo $(t i / r) / t e$ - en función de interrogativo. Al revés que en castellano, la curva melódica es descendente.

(8) ¿Viven tus padres?
a) i? A-ye-yeu-ma
2SG:POS-PL-padre-PL
b) ?A-ye-yeu-ma
me-pi-wiikwé?
3PL:SUJ:ANIM-PRIM-estar.vivo
2SG:POS-PL-padre-PL
me-te-wiikwé.
3PL:SUJ-SUJ.PL:PREG-estar.vivo
[Construcción del Ensayo]
[Construcción correcta]

En el texto huichol hay algunas construcciones con el prefijo interrogativo, lo que muestra que el traductor sí conocía la construcción interrogativa del tipo b) y que las construcciones sin el prefijo interrogativo son un efecto de las condiciones en que se lleva a cabo la traducción. En (9) se impuso la competencia del hablante:

(9) ¿Cómo se llamaron? (los hijos de Abraham)

¿Ke=me-te-'u-ta-tewa-rí-xì? (Lit. "como fueron bautizados")

Q-3PL:SUJ:ANIM-PREG:SUJ.PL-EXP-UNIT-nombrar-PAS-PERF

\section{La adecuación tipológica}

Una traducción palabra por palabra entre español y huichol no es posible puesto que son lenguas con una estructura muy diferente. La traducción pierde calidad y se vuelve inconprensible si no se atiene a las características tipológicas generales. El criterio de conformidad tipológica es tanto más relevante cuanto más distantes son las lenguas en el espacio tipológico. ¿Cómo se traduce del español, una lengua predominantemente nominal, fusionante y menos explícita, a una lengua como huichol polisintética, centralizante, verbalizante y explicitante, que tiende a hacer coextensivos la oración y el predicado? (Iturrioz/Gómez/Ramírez 2004; Iturrioz/Gómez 2006: cap. 3). La proporción de ocurrencias de unidades sintácticas por categorías léxicas no corresponde a la de los textos huicholes, donde en general aparecen en promedio cuatro palabras predicativas (casi siempre verbales) por una referencial. 
Bajo la presión del español, en el catecismo se presenta un $25 \%$ más de palabras referenciales que predicativas.

Las lenguas europeas que han participado en el proceso de formación de la cultura técnica occidental, se caracterizan por un estilo nominal. El huichol y otras lenguas americanas son lenguas centradas más en el evento que en los participantes o los objetos.

\section{La competencia textual}

Un texto es mucho más que una cadena o secuencia de oraciones, éstas deben integrarse en unidades más complejas con cohesión formal y coherencia temática. Es cierto que un texto se construye con oraciones particulares, pero es igualmente cierto que cada oración debe ser construída de manera que quede ligada al texto tanto formal como semántica y pragmáticamente. El traductor debe además armar en la lengua meta textos ajustados a las características de las tradiciones discursivas propias. ¿Cómo se traduce al huichol un texto técnico de lingüística o un texto legal si carece de las correspondientes tradiciones discursivas? Generar estilos funcionales nuevos implica poner en marcha desarrollos culturales, institucionales y cognitivos.

Las formulaciones pueden ser más o menos coloquiales o formales, lo que puede influir considerablemente en la comprensión. Pero la ubicación entre estos dos extremos puede variar de una parte a otra del texto; la alternancia de estilos puede ser muy positiva desde el punto de vista pedagógico. Todas las opciones pueden ser usadas, dependiendo de si se trata de la definición de un término o de un ejercicio, de una explicación práctica. En un caso se busca el acercamiento al nivel de conocimientos del lector, en otros se trata de atraer al lector hacia un nivel de conocimientos más elevado.

El traductor debe aprender a alternar inteligentemete los dos estilos. La traducción de un catecismo, de una ley y de un texto lingüístico implica recurrir a códigos diferentes, y dentro de un mismo texto se puede dar una alternancia de códigos mediante un juego de reformulaciones. Todo código verbal abarca un conjunto de subcódigos o variedades funcionales, ordenables en una escala entre la explicitud máxima y la elipsis máxima.

En la alternancia de código o registro intervienen factores pragmáticos, puesto que el uso de las variantes debe atender también reglas que corresponden a distintas estrategias de la comunicación. La competencia gramatical se debe englobar en un concepto más abarcador de competencia comunicativa (Hymes 1992), de la que depende si las emisiones de cualquier complejidad son o no apropiadas para codificar un mensaje en una circunstancia determinada o en un tipo de texto determinado.

\section{La competencia cultural}

Un texto es una construcción cultural. (Giuliani 1979) La competencia cultural va más allá del significado de los signos lingüísticos y las convenciones comunica- 
tivas, y abarca el dominio de un tema o un área de conocimiento. Un ejemplo de falta de competencia cultural lo tenemos en la confusión que al traductor del catecismo le debieron generar las explicaciones del clérigo para que entendiera la noción de pecado mortal como causante de la muerte del alma. El texto original del catecismo dice "¿Dónde van las almas de los buenos cuerpos cuando mueren?", pero la frase en huichol significa otra cosa:

(11) Hakewa peyeika wakipuri memikaxirikítika, memikatikuukuwe. “¿Dónde van las almas de los que no están sucios, de los que no mueren?”

donde "los que no mueren" se debe interpretar de vuelta como "los que no han cometido pecado mortal". La traducción implica insertar la semántica textual en un dominio cultural y cognitivo que el traductor no conocía en profundidad.

\section{Conclusiones}

La traducción es una operación lingüística compleja que integra e interrelaciona todos los subsistemas de organización de las lenguas. Además del conocimiento del léxico y la gramática, el traductor debe poseer una competencia comunicativa y textual.

En texto es una operación comunicativa compleja en la que desempeñan un papel importante la pragmática, la tipología de textos y el contexto cultural. La competencia restringida a la capacidad de generar oraciones bien formadas no puede dar cuenta de ese proceso.

No existe una sola manera de traducir un término, sino varias o muchas alternativas de expresar lo mismo según la situación, el registro elegido, la pragmática textual. La semántica no se puede restringir al significado de las palabras, ya que la oración y el texto son también niveles de construcción del significado.

Además, son muy relevantes las consideraciones de orden tipológico, y la importancia de la competencia cultural se hace tanto más evidente cuanto más diferentes son las respectivas culturas.

\section{Referencias bibliográficas}

Giuliani, M.V. et al., «Speculations on text as a linguistic and cultural construct», en: Petöfi, J.S. (ed.), Text vs sentence, basic questions of text linguistics. Hamburg: Buske 1979, 170-180. Hymes, D., «The concept of communicative competence revisited», en Pütz, M. (ed.),

Thirty Years of Linguistic Evolution. Amsterdam/Philadalphia: John Benjamins 1992, 31-58. Iturrioz Leza, J.L. (en prensa), «Características tipológicas fundamentales del huichol», en:

Dakin, K., Estrada, Z. \& Moctezuma, J.L. (eds.), Lenguas Yutoaztecas: Acercamientos a su Diversidad Lingüistica. Hermosillo, Son.: U. de Sonora, México.

Iturrioz Leza, J.L., Gómez López, P. \& Ramírez de la Cruz, X., «La morfología verbal», en: Iturrioz, J.L. (coord.), Lenguas y Literaturas Indígenas de Jalisco. México: CONACULTA 2004, 171-204. 
Iturrioz Leza, J.L., Gramática Didáctica el Huichol. Guadalajara: U. de Guadalajara, México 2000.

Iturrioz Leza, J.L., «Reconstrucción del contacto entre huichol y español a través del análisis diacrónico de los préstamos», UniverSOS 5 (2008), 169-192.

Iturrioz Leza, J.L. y Gómez López, P., Gramática Wixarika I. Múnich: Lincom 2006.

Jakobson, R., «En torno a los aspectos lingüísticos de la traducción», en: Jakobson, R., Ensayos de Lingüistica General. Barcelona: Seix Barral 1981 (1959), 67-77.

Nida, E.A., «Principles of translation as exemplified by bible translating», en: Brower, R.A. (ed.), On Translation. London: Oxford University Press 1959.

Roble, F. de P. y Velasco, M., Ensayo Catequístico en Español y Huichol. Zacatecas 1906.

Rojas, B., Los huicholes en la historia. Zamora: INI - Colegio de Michoacán 1993.

\section{Abreviaturas}

$\begin{array}{llll}2 & \text { segunda persona } & \text { PL } & \text { plural } \\ 3 & \text { tercera persona } & \text { POS } & \text { posesión } \\ \text { AMPL } & \text { ampliador de dominios } & \text { PREG } & \text { pregunta } \\ \text { ANIM } & \text { animado } & \text { PRIM } & \text { modalidad primaria, de } 1^{\text {a }} \text { persona } \\ \text { EXP } & \text { experiencial } & \text { Q } & \text { requerimiento: orden o pregunta } \\ \text { FIG } & \text { figura } & \text { REFL } & \text { reflexivo } \\ \text { IMPS } & \text { impersonal } & \text { SEC } & \text { modalidad secundaria de } 2^{\text {a }} \text { persona } \\ \text { OBJ } & \text { objeto } & \text { SG } & \text { singular } \\ \text { PAC } & \text { paciente } & \text { SUJ } & \text { sujeto } \\ \text { PAS } & \text { pasiva } & \text { TERM } & \text { terminativo } \\ \text { PERF } & \text { perfectivo } & \text { UNIT } & \text { unitario }\end{array}$

